ARTICLE

DOI: $10.1038 / \mathrm{s} 41467-017-00747-6$

OPEN

\title{
MRAP2 regulates ghrelin receptor signaling and hunger sensing
}

Dollada Srisai 1,2,3, Terry C. Yin 1,2,3, Abigail A. Lee ${ }^{1,2,3}$, Alix A.J. Rouault ${ }^{1,2,3}$, Nicole A. Pearson ${ }^{2,4}$, Justin L. Grobe ${ }^{2,4}$ \& Julien A. Sebag (i) ${ }^{1,2,3}$

Ghrelin is the only known circulating orexigenic hormone. It is primarily secreted by the stomach and acts at its receptor, the growth hormone secretagogue receptor 1a (GHSR1a), in the hypothalamus to signal hunger and promote food intake. The melanocortin receptor accessory protein 2 (MRAP2) was previously shown to regulate energy homeostasis through the modulation of the activity of the melanocortin-4 receptor and prokineticin receptors. In this study we identify MRAP2 as a partner of ghrelin-GHSR1a signaling. We show that MRAP2 interacts with GHSR1a and potentiates ghrelin-stimulated signaling both in vitro and in vivo. We demonstrate that in the absence of MRAP2, fasting fails to activate agouti-related protein neurons. In addition, we show that the orexigenic effect of ghrelin is lost in mice lacking MRAP2. Our results suggest that MRAP2 is an important modulator of the energy homeostasis machinery that operates through the regulation of multiple GPCRs throughout the hypothalamus.

\footnotetext{
${ }^{1}$ Department of Molecular Physiology and Biophysics, University of lowa, Carver College of Medicine, lowa City, IA 52242, USA. ${ }^{2}$ F.O.E.D.R.C, lowa City, IA 52242, USA. ${ }^{3}$ Pappajohn Biomedical Institute, lowa City, IA 52242, USA. ${ }^{4}$ Department of Pharmacology, University of lowa, Carver College of Medicine, lowa City, IA 52242, USA. Dollada Srisai and Terry C. Yin contributed equally to this work. Correspondence and requests for materials should be addressed to J.A.S. (email: Julien-sebag@uiowa.edu)
} 
F ood intake and energy expenditure are tightly regulated by numerous hormones and neuropeptides secreted either by peripheral organs or centrally ${ }^{1,2}$. These molecules act on the hypothalamus, through their respective receptors, to inform the brain on the energy state of the organism. Ghrelin is a peptide hormone secreted by the stomach ${ }^{3}$ during fasting to signal hunger to the brain ${ }^{4,5}$. Ghrelin acts through its receptor, the growth hormone secretagogue receptor la (GHSR1a), a G-protein-coupled receptor (GPCR) expressed in the hypothalamus, in particular in orexigenic agouti-related protein (AGRP) neurons ${ }^{5-8}$. Ghrelin function has been shown to be largely mediated through and to require AGRP neurons ${ }^{5,9}$. Whereas several GPCRs have been shown to be regulated by or to require the presence of accessory proteins, the interaction of GHSR1a with accessory proteins has not been investigated.

The melanocortin receptor accessory protein 2 (MRAP2) is a single transmembrane protein that plays an important role in the control of energy homeostasis since the deletion of MRAP2 in mice causes severe obesity ${ }^{10}$. Mutations in MRAP2 have also been identified in obese humans ${ }^{10}$. MRAP2 is highly expressed in the hypothalamus where it is known to regulate the activity of the melanocortin-4 receptor ${ }^{10,11}$ and the prokineticin receptors ${ }^{12}$, GPCRs, that signal satiety and are required for the proper control of food intake and energy expenditure ${ }^{12-16}$. In this study we investigated if MRAP2 modulates ghrelin signaling in vitro and in vivo, and conclude that MRAP2 interacts with GHSR1a and is an important component of the ghrelin receptor signaling complex, thus establishing that in addition to being a regulator of satiety sensing through the modulation of MC4R and PKR1 activity, MRAP2 promotes hunger sensing by potentiating ghrelin signaling.

\section{Results}

MRAP2 deletion reduces physiological response to starvation. As previously reported, Mrap2 knockout (KO) mice develop obesity and their weight start diverging from wild-type (WT) animals between 9 and 11 weeks of age ${ }^{10}$. To identify the cause of the obesity phenotype, we investigated how deleting MRAP2 impacts energy homeostasis in 11- to 13-week-old mice. At this age, Mrap2 KO animals were slightly but significantly heavier than their WT littermates (Fig. 1a). Mrap2 KO mice displayed no increase in daily food intake (Fig. 1b), digestive efficiency (Fig. 1c), or heat production (Fig. 1d). However, we found that Mrap2 KO mice have a significant decrease in locomotor activity compared to WT littermates (Fig. 1e, f), suggesting that the obesity caused by MRAP2 deletion is, at least in part, due to decreased activity. While we observed no significant difference in daily food intake (Fig. 1b) or accumulated food intake (Fig. 1g) between WT and Mrap2 KO mice, we found that mice lacking MRAP2 eat about 30\% less food compared to their WT littermates in the day following a $24 \mathrm{~h}$ fast (Fig. 1h), thus suggesting that MRAP2 is important for hunger sensing and that Mrap2 KO mice experience a weaker drive to eat following a fast.

The hypothalamus plays a critical role in the control of energy homeostasis, and the orexigenic AGRP neurons of the arcuate nucleus (ARC) are essential for sensing energy needs and signaling hunger ${ }^{17}$. Given our finding that the deletion of MRAP2 leads to a decrease in food intake following a fast, we hypothesized that MRAP2 is important for the starvationmediated activation of orexigenic AGRP neurons. To test this hypothesis we measured the expression of several markers of AGRP neuron activation in the ARC of ad libitum-fed or $24 \mathrm{~h}$ fasted WT and Mrap2 KO mice. We first measured cFos expression. For this, both satiated and fasted animals were sacrificed shortly after the start of the light phase and brains were harvested and sliced for immunofluorescence imaging. Brain slices were then stained for the expression of $\mathrm{cFos}$, a transcription factor that is encoded by an immediate early gene and marks activated neurons. Neuronal activation in the ARC was quantified by counting cFos-positive cells for each condition and genotype. As previously demonstrated ${ }^{18}$, in WT animals the number of cFos positive neurons in this brain region is dramatically
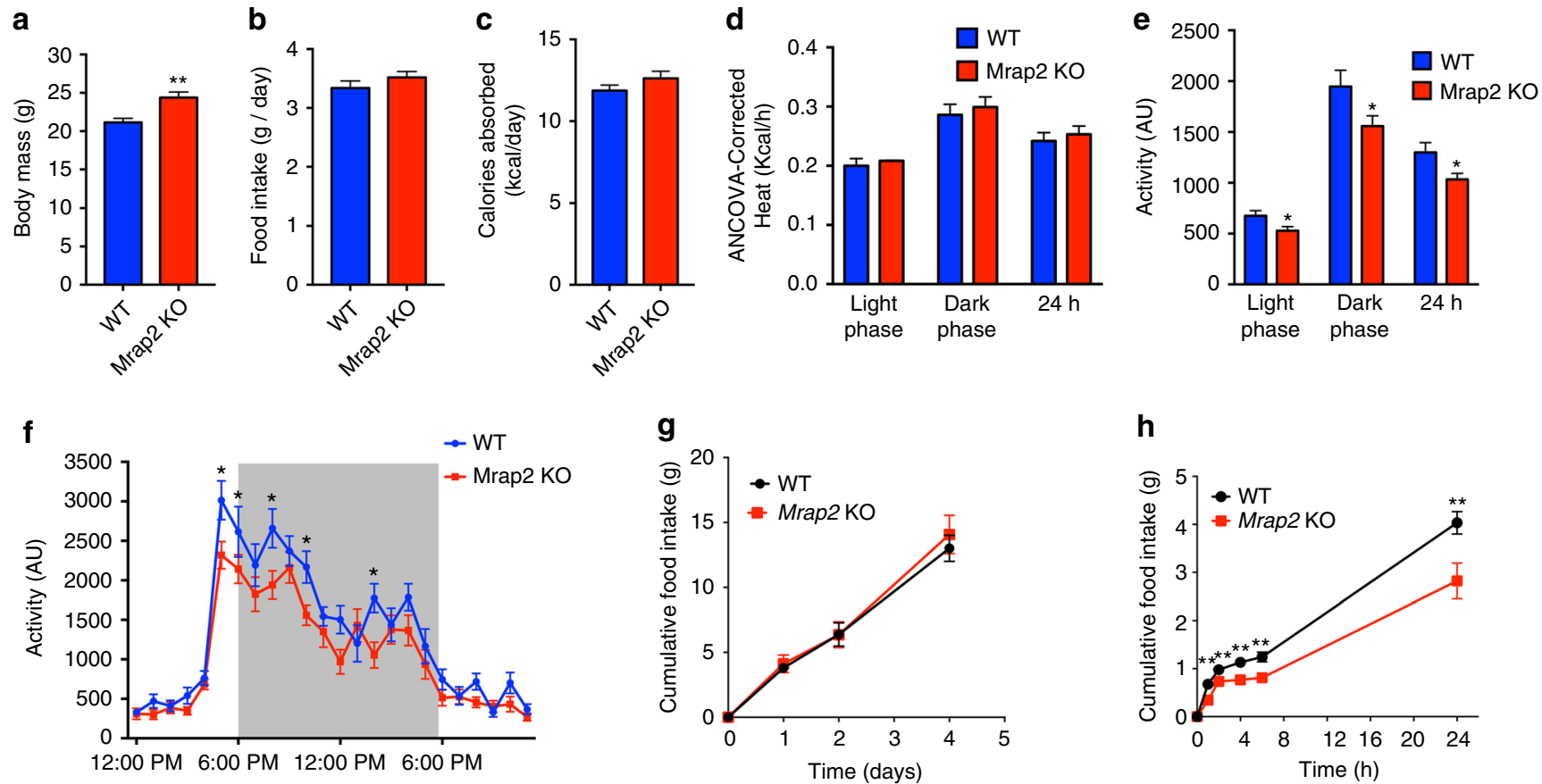

Fig. 1 Mrap2 KO mice display decreased locomotor activity. a Body mass of 12- to 13-week-old WT ( $n=12$ ) and Mrap2 KO ( $n=13$ ) male mice. b Daily food intake of WT and Mrap2 KO mice. c Daily calories absorbed by WT and Mrap2 KO mice. d ANCOVA-corrected energy expenditure of WT and Mrap2 KO mice. e Activity of WT and Mrap2 KO mice. f Hourly activity of WT and Mrap2 KO mice. $\mathbf{g}$ Cumulative food intake (regular diet) of WT and Mrap2 KO mice over 5 days. h Cumulative food intake (regular diet) of WT and Mrap2 KO mice after a $24 \mathrm{~h}$ fast. Error bars are SEM. ${ }^{\star} P<0.05,{ }^{\star} P<0.01$ 

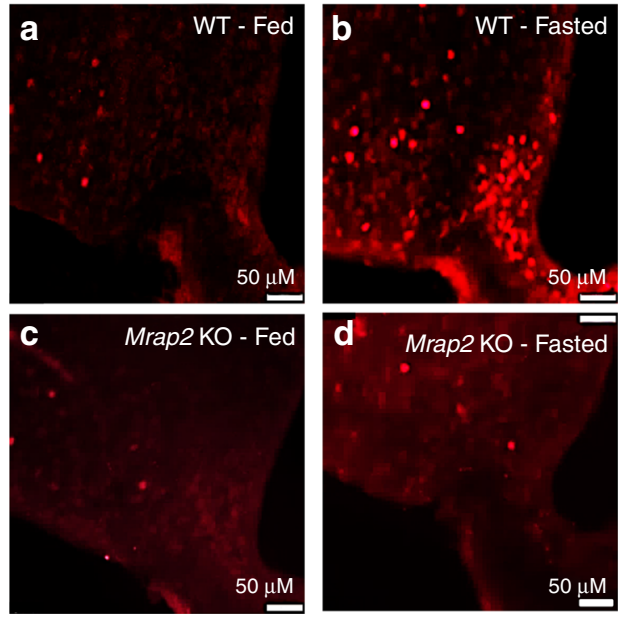

$\mathbf{e}$
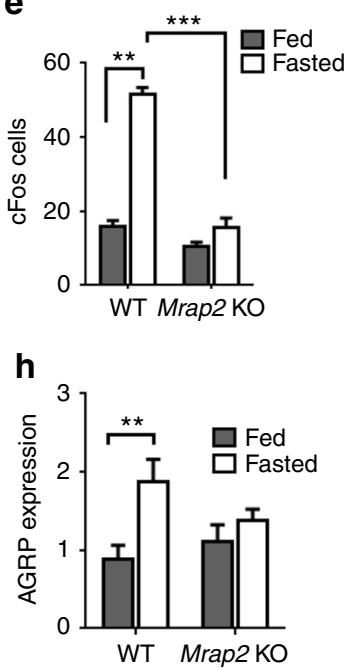

f

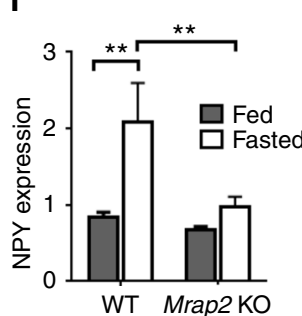

g

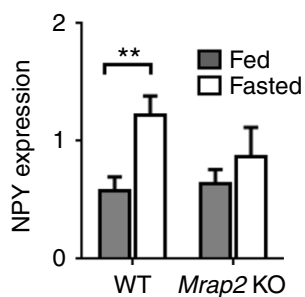

i

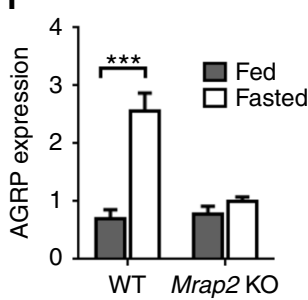

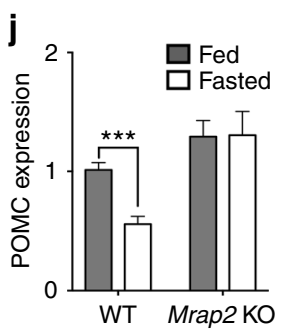
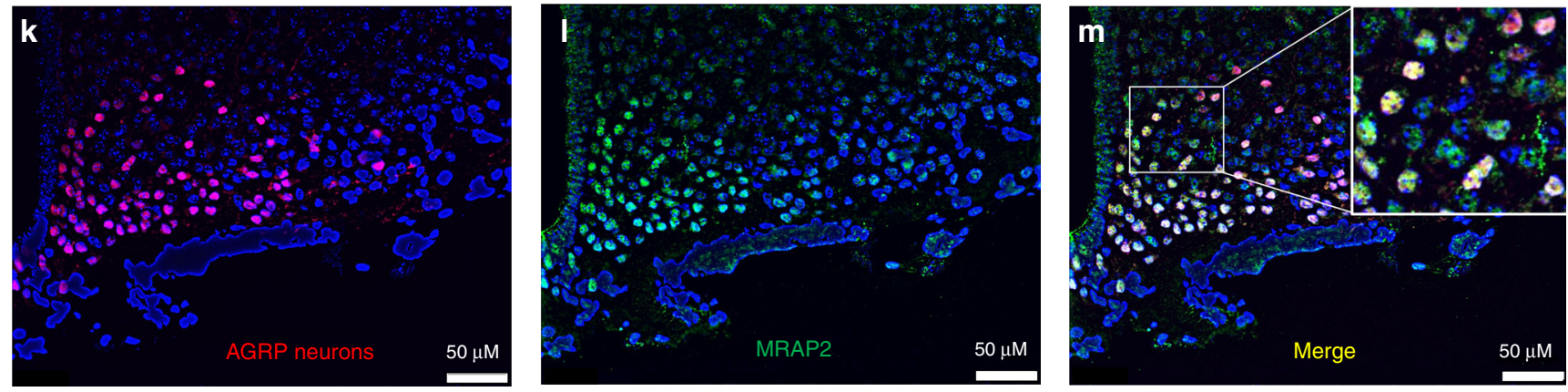

Fig. 2 MRAP2 is important for the stimulation of AGRP neurons by fasting. a-d cFos expression in the arcuate nucleus of fed WT (a), $24 \mathrm{~h}$-fasted WT (b), fed Mrap2 KO (c), and $24 \mathrm{~h}$-fasted Mrap2 KO (d) mice. e Quantitative measurement of cFos activation in the arcuate nucleus of fed or fasted WT and Mrap2 KO mice. f, $\mathbf{g}$ NPY expression measured by qPCR in the arcuate nucleus of male (f) and female (g) fed or $24 \mathrm{~h}$-fasted WT and Mrap2 KO mice. $\mathbf{h}$, $\mathbf{i}$ AGRP expression measured by qPCR in the arcuate nucleus of male (h) and female (i) fed or $24 \mathbf{h}$-fasted WT and Mrap2 KO mice. $\mathbf{j}$ POMC expression measured by qPCR in the arcuate nucleus of male fed or $24 \mathrm{~h}$-fasted WT and Mrap2 KO mice. $\mathbf{k}$-m Colocalization of AGRP (k) and MRAP2 (I) by immunofluorescence microscopy in the arcuate nucleus. AGRP neurons expressing MRAP2 are shown in yellow in the merged image (m). Error bars are SEM. ${ }^{\star \star *} p<0.001,{ }^{\star \star} p<0.01$

increased by fasting (Fig. 2a, b, e). In the Mrap2 KO mice, however, the activation of AGRP neurons by fasting was almost completely prevented; no significant difference in cFos expression was detected between the ARC of fasted vs. fed Mrap2 KO mice (Fig. 2c, d, e). A second readout of the activation of AGRP neurons is the expression of genes encoding the orexigenic neuropeptides AGRP and NPY; the expression of both neuropeptides in AGRP neurons is upregulated by fasting to promote food intake by either inhibiting MC4R or activating neuropeptide (NPY) receptors ${ }^{19}$. Whereas fasting resulted in a significant increase in Agrp and Npy gene expression in WT animals, this was not the case in Mrap2 $\mathrm{KO}$ animals (Fig. 2f-i). Interestingly, the deletion of MRAP2 does not only affect AGRP neurons but also proopiomelanocortin (POMC) neurons since the decrease in Pomc expression caused by fasting is absent in Mrap2 $\mathrm{KO}$ mice (Fig. 2j). Altogether, these results support the hypothesis that MRAP2 regulates central hunger sensing, since the deletion of MRAP2 impairs the starvation response in the ARC.

MRAP2 is expressed in AGRP neurons. Although it is clear that MRAP2 is expressed in the hypothalamus, its expression within the AGRP neurons has only been shown at the transcriptional level $^{20}$. For this reason we performed immunofluorescence detection of MRAP2, using a previously extensively validated anti-MRAP2 antibody ${ }^{12}$, in brain slices from mice expressing
tdTomado in AGRP neurons (AGRPCRE/tdTomato mice). We show that MRAP2 is expressed throughout the hypothalamus, including AGRP neurons (Fig. 2k-m).

MRAP2 deletion in AGRP neurons impairs starvation sensing. To determine if the deletion of MRAP2 specifically in AGRP neurons is sufficient to prevent fasting-induced cFos expression in the ARC, we bred AGRPCRE mice with MRAP2 ${ }^{\text {floxed }}$ mice and compared cFos expression by immunofluorescence in the ARC of fed or $24 \mathrm{~h}$-fasted AGRPCRE/MRAP2 ${ }^{+/+}$(control) or AGRPCRE/ MRAP $2^{\mathrm{fl} / \mathrm{fl}}$ mice. Consistent with a specific deletion of MRAP2 in AGRP neurons, the expression of MRAP2 in microdissected ARC from $A G R P C R E / M R A P 2$ fl/fl mice is about half of that of AGRP $^{\text {CRE}} / \mathrm{MRAP}^{+/+}$animals (Fig. 3a). Unlike the global Mrap2 $\mathrm{KO}$ animals, AGRPCRE $/ \mathrm{MRAP}^{\mathrm{fl} / \mathrm{fl}}$ mice do not develop obesity (Supplementary Fig. 1). We found that like MRAP2 KO mice, $\mathrm{AGRP}^{\mathrm{CRE}} / \mathrm{MRAP}^{\mathrm{fl} / \mathrm{fl}}$ mice eat significantly less after a $24 \mathrm{~h}$ fast compared to the AGRPCRE $/ \mathrm{MRAP}^{+/+}$control animals (Fig. 3b). Additionally, whereas fasting potently induced cFos expression in the ARC of AGRPCRE/MRAP2 ${ }^{+/+}$mice, no significant increase in cFos expression was measured in AGRPCRE /MRAP2 ${ }^{\mathrm{fl} / \mathrm{fl}}$ animals (Fig. $3 \mathrm{c}-\mathrm{g}$ ). These results suggest that MRAP2 is required within AGRP neurons for their activation by fasting.

Although numerous circulating hormones inform the brain about the energy state, most suppress food intake (e.g. insulin, 

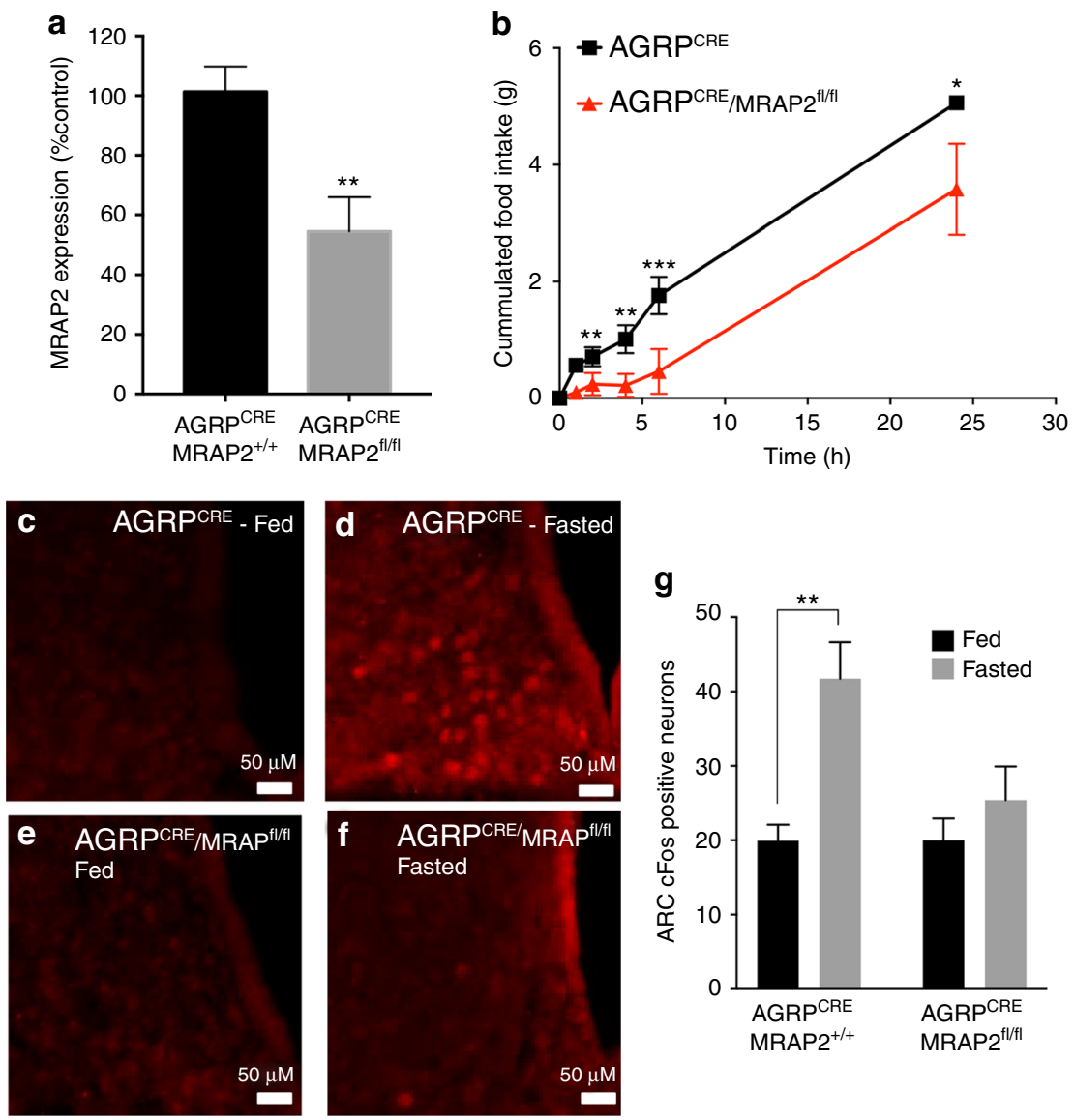

Fig. 3 MRAP2 is important within AGRP neurons for starvation sensing. a qPCR measurement of MRAP2 expression in the ARC of AGRPCRE/MRAP2 ${ }^{+/+}$ and AGRPCRE $/ \mathrm{MRAP2}^{\mathrm{fl} / \mathrm{fl}}$ mice. $\mathbf{b}$ Food intake after a $24 \mathrm{~h}$ fast in AGRPCRE$/ \mathrm{MRAP}^{+/+}$and AGRPCRE$/ \mathrm{MRAP} 2^{\mathrm{fl} / \mathrm{fl}}$ mice $\left(n=8 \mathrm{AGRPCRE} / \mathrm{MRAP2}^{+/+}, n=5\right.$ AGRPCRE $\left./ M_{R A P 2}{ }^{f l / f l}\right)$. c-f Immunofluorescent detection of cFos expression in the arcuate nucleus of fed or fasted AGRPCRE $/ M R A P 2^{+/+}$and AGRPCRE/MRAP2 ${ }^{\text {fl/fl }}$ mice. $g$ Quantification of fasting-induced cFos expression in the arcuate nucleus of AGRPCRE $/ \mathrm{MRAP2}^{+/+}$and AGRPCRE $/ \mathrm{MRAP}^{\mathrm{fl} / \mathrm{fl}}$ mice ( $n=3$ /group). Error bars are SEM. ${ }^{\star \star \star} p<0.001,{ }^{\star \star} p<0.01,{ }^{\star} p<0.05$

cholecystokinin, leptin, and peptide YY $)^{21}$. By contrast, ghrelin is the only known circulating hormone that promotes food intake ${ }^{22}$. AGRP neurons express GHSRla and are the main target of systemic ghrelin. Since fasting induces cFos activation in the ARC of GHSR1a KO mice (Supplementary Fig. 2), it is clear that a loss of ghrelin signaling does not result in a complete impairment of fasting-induced activation of AGRP neurons. However, due to the role of the ghrelin system in transmitting starvation signals to AGRP neurons and the regulatory function of MRAP2 on several GPCRs, we investigated how MRAP2 impacts GHSR1a function and signaling.

MRAP2 interacts with GHSR1a in vitro. We tested the ability of MRAP2 to form a complex with the ghrelin receptor using HEK293T cells transfected with 3 hemaglutinin (HA)-tagged GHSR1a (3HA-GHSR1a) and 3xFlag-tagged MRAP2 (MRAP23F). Transfected cells were lysed and the GHSR1a or MRAP2 were pulled down using monoclonal anti-HA or anti-Flag antibody, respectively. Western blotting revealed reciprocal coimmunoprecipitation (Fig. 4a, b; full-size western blot shown in Supplementary Fig. 4). Specificity of the interaction was confirmed by the fact that in samples lacking the immunoprecipitating antibody (beads alone), neither GHSR1a nor MRAP2 was detected by western blotting. To further determine if MRAP2 and GHSR1a can form a complex in live cells while decreasing the risk of overexpression artefacts, we took advantage of the NanoBit protein-protein interaction assay. This assay relies on the recombination of two fragments, LgBit and SmlBit, of the bright NanoLuc luciferase fused to the proteins of interest. In this case we fused LgBit to the C-terminal region of 3HA-GHSR1a and SmlBit to the C terminus of MRAP2. The low intrinsic affinity of the NanoBit fragments for each other ensures that the dimerization of the proteins studied is required for the luciferase to reform. In addition, the brightness of the NanoLuc enzyme allows those protein-protein interaction experiments to be performed at low expression levels and thus prevent overexpression artefacts. This is achieved by driving the expression of the fusion proteins with a weak promoter (HSV-TK). We show that in mock transfected cells or in cells transfected with either GHSR1a-LgBit or MRAP2-SmlBit along with a non-interacting protein fused to the complementary fragment of NanoLuc (negative controls), very little luminescence is detected. In cells transfected with both GHSR1a-LgBit and MRAP2-SmlBit however, we are able to detect a very high luminescence signal (Fig. 4c), thus confirming that GHSR1a and MRAP2 can specifically form a complex in live cells. To verify that the expression level of 3HA-GHSR1a-LgBit used for the NanoBit assay was indeed lower than the GHSR1a driven by the cytomegalovirus (CMV) promoter used for the coimmunoprecipitation experiment, we transfected cells with either construct and assessed the expression level by western blot using anti-HA antibody (both constructs include an N-terminal 3XHA tag). While the CMV-driven 3HA-GHSR1a protein was readily detectable we were barely able to detect the HSV-TK-driven 
3HA-GHSR1a-LgBit protein (Fig. 4d), thus confirming that GHSR1a and MRAP2 can specifically interact in live cells even at a low expression level.

Given that MRAP2 interacts with GHSR1a, we tested whether it could modulate the density of the receptor at the cell surface. a

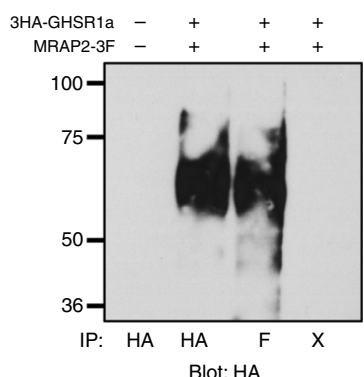

C

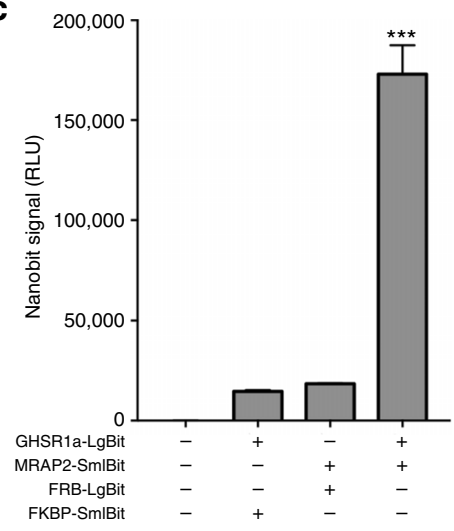

e

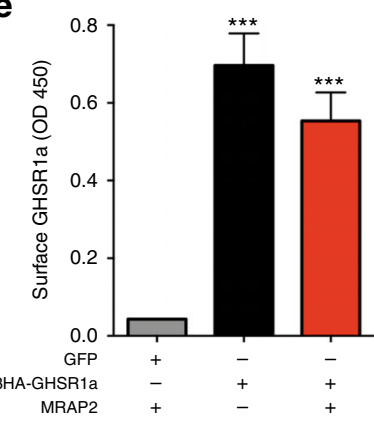

\section{b}

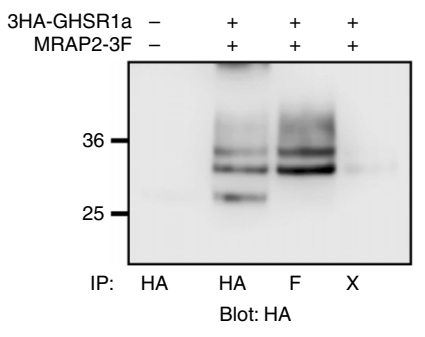

d
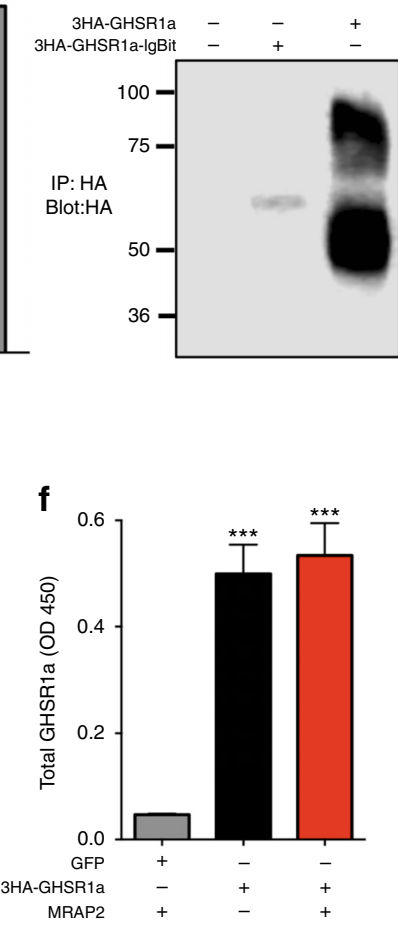

g

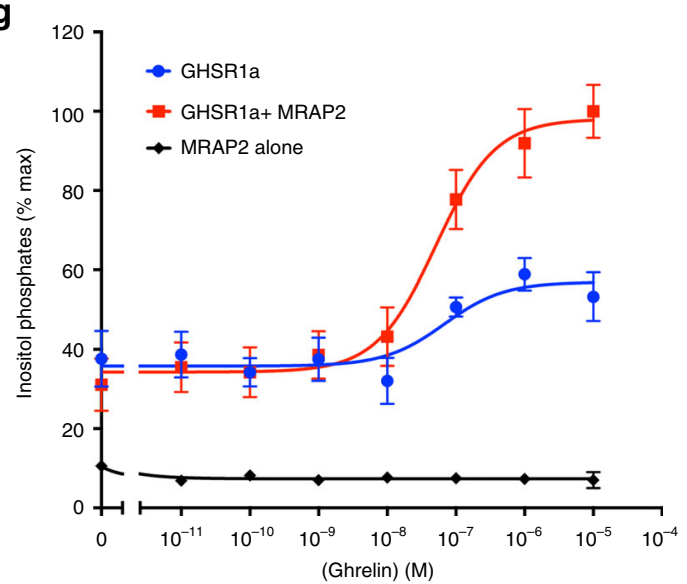

To this end we transfected Chinese hamster ovary $(\mathrm{CHO})$ cells with 3HA-GHSR1a and either MRAP2 or green fluorescent protein (GFP; as a control). We then fixed the cells and measured both cell-surface (in non-permeabilized cells) and total (in permeabilized cells) expression of 3HA-GHSR1a by fixed-cell enzyme-linked immunosorbent assay (ELISA). MRAP2 had no significant effect on either the cell surface density or total GHSR1a expression (Fig. 4e, f). Thus, MRAP2 does not appear to regulate trafficking of the ghrelin receptor.

MRAP2 potentiates ghrelin-stimulated GHSR1a signaling. We next tested if MRAP2 modulates GHSR1a signaling. Since GHSR1a couples to the G-protein $G \alpha_{\mathrm{q} / 11}$, we measured ghrelininduced inositol triphosphate (IP3) production (reported by the concentration of accumulated inositol phosphates) in $\mathrm{CHO}$ cells expressing MRAP2, GHSR1a, or GHSR1a and MRAP2. As expected, ghrelin does not stimulate IP3 production in cells only expressing MRAP2. In cells expressing GHSR1a, we found that the efficacy of the ghrelin-induced IP3 response was greatly enhanced by the presence of MRAP2 (Fig. 4g). This finding demonstrates that MRAP2 potentiates GHSR1a activity, and suggests that the attenuated signaling downstream of GHSR1a in cells lacking MRAP2 may in part account for the defect in hunger sensing observed in MRAP2 KO mice. To test this hypothesis in vivo we measured the ability of ghrelin to activate AGRP neurons in the ARC of WT and Mrap2 KO mice. To this end we injected ad libitum-fed WT and Mrap2 KO animals with ghrelin or saline intraperitoneally before harvesting the ARC and measuring AMPK phosphorylation, a protein activated by ghrelin in AGRP neurons, by western blot. We found that as expected, ghrelin induced AMPK phosphorylation in WT animals (Fig. 5a, b). In Mrap2 KO mice, however, the level of pAMPK was constitutively elevated but was not further increased by ghrelin, thus suggesting that ghrelin does not activate AGRP neurons in mice lacking MRAP2. To confirm this finding we performed intracerebroventricular (ICV) injections of ghrelin or saline in mice cannulated in the lateral ventricle of the brain and harvested the brains for immunofluorescence staining of cFos. Injection with ghrelin caused a significant increase in the number of cFospositive neurons in the ARC compared to saline regardless of genotype. However, the response to ghrelin in Mrap2 KO mice was about half of that in WT littermates (Fig. 5c-g), thus confirming that the deletion of MRAP2 causes a significant impairment of GHSR1a signaling in vivo and prevents the efficient activation of AGRP neurons by ghrelin.

MRAP2 potentiates GHSR1a signaling in AGRP neurons. To test whether the potentiation of ghrelin-stimulated signaling by MRAP2 observed in vitro takes place in AGRP neurons, we recorded the calcium response elicited by ghrelin in AGRP neurons of AGRPCRE $/ \mathrm{MRAP}^{+/+}$and AGRPCRE$/ \mathrm{MRAP}^{\mathrm{fl} / \mathrm{fl}}$ mice. To this end, AGRPCRE $/ \mathrm{MRAP}^{+/+}$and AGRPCRE $/ \mathrm{MRAP}^{\mathrm{fl} / \mathrm{fl}}$ mice were stereotaxically injected with adeno-associated viruses coding

Fig. 4 MRAP2 interacts with and potentiates the activity of the GHS-R1a. a, b Co-immunoprecipitation of lysates from HEK293T cells transfected with 3HA-GHSR1a and MRAP2-3Flag. c Measurement of GHSR1a and MRAP2 interaction in live cells using the NanoBit assay. $\mathbf{d}$ Western blot detection of 3HA-GHSR1a and 3HA-GHSR1a-LgBit transfection in CHO cells. e Surface expression of GHSR1a in CHO cells transfected with 3HA-GHSR1a with or without MRAP2. $\mathbf{f}$ Total expression of GHSR1a in $\mathrm{CHO}$ cells transfected with 2HA-GHSR1a with or without MRAP2. $\mathbf{g}$ Ghrelin-induced IP3 production as measured by IP1 accumulation in CHO-M1 cells transfected with MRAP2, 3HA-GHSR1a alone (empty vector), or GHSR1a with human MRAP2. Error bars are SEM. ${ }^{\star \star \star} p<0.001$ 
a

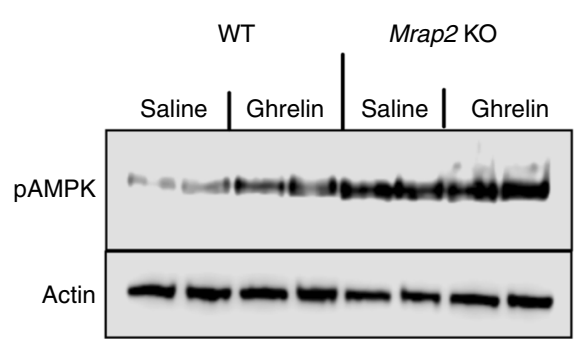

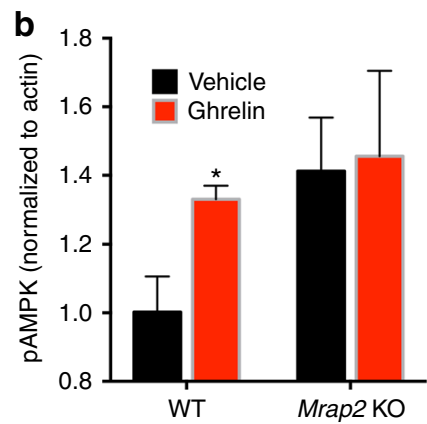
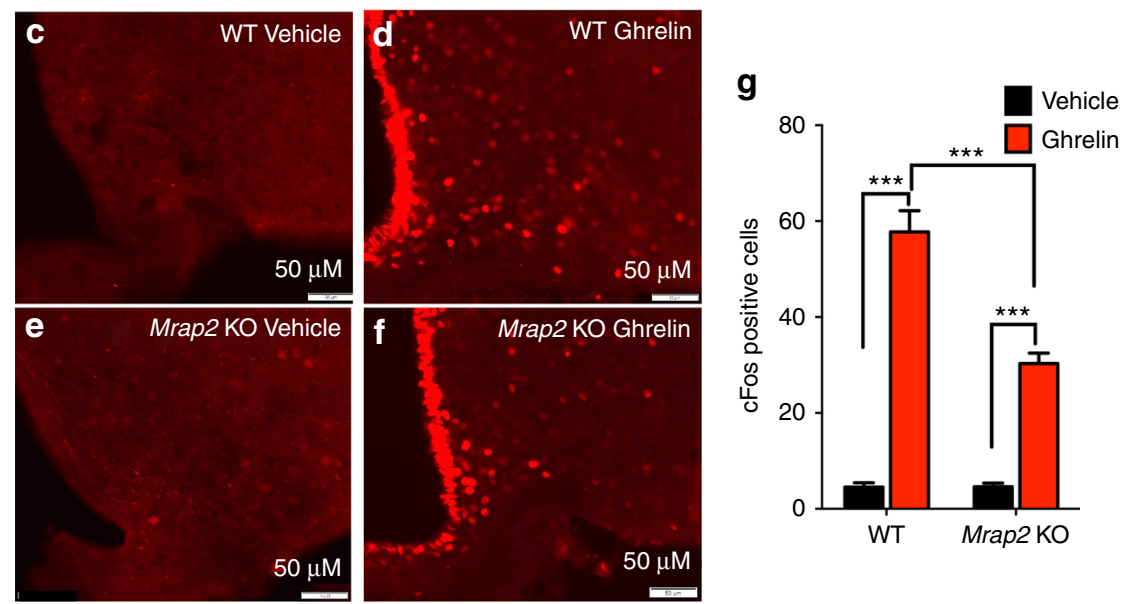

Fig. 5 MRAP2 potentiates the activity of the GHS-R1a in the hypothalamus. a, b Western blot (a) and densitometry analysis (b) of AMPK phosphorylation and actin expression (loading control) in the ARC of WT and Mrap2 KO mice injected IP with saline or ghrelin. $n=4 /$ group. c- $\mathbf{f}$ Induction of cFos expression in ARC neurons of WT and Mrap2 KO mice by ICV injection of saline or ghrelin. cFos expression in ARC neurons was detected by immunofluorescence in WT (c, d) or Mrap2 KO (e, f) animals following ICV injection of saline or $13.5 \mu \mathrm{g}$ ghrelin. cFos induction in each condition was quantified and represented as mean $\pm \operatorname{SEM}\left(n=5 /\right.$ group) (g). Error bars are SEM. ${ }^{\star} p<0.05,{ }^{\star \star *} p<0.001$
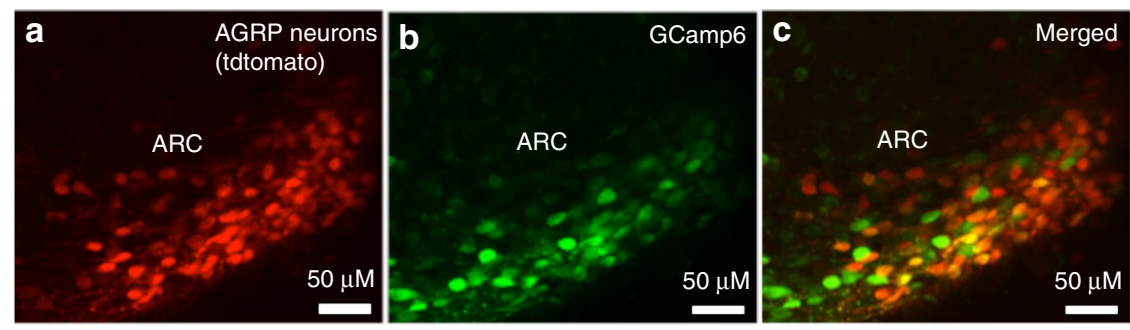

d

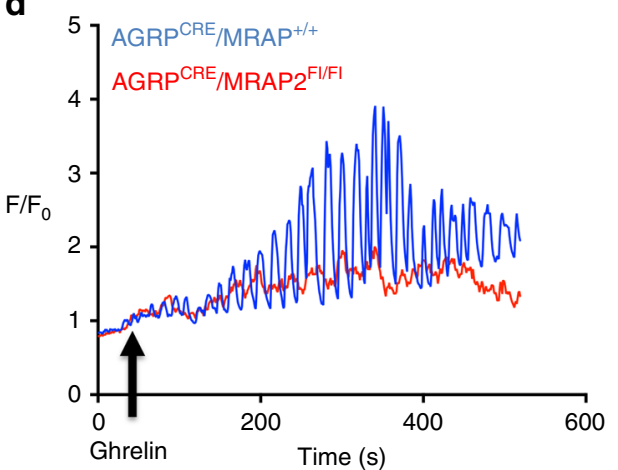

e

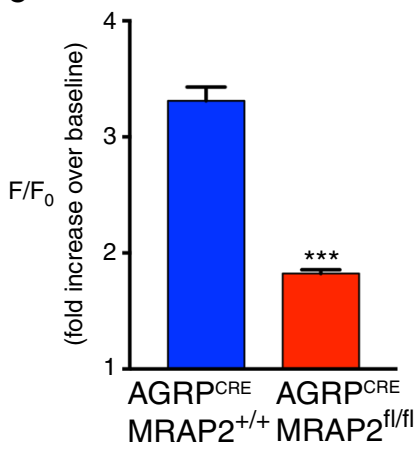

Fig. 6 MRAP2 potentiates the ghrelin-stimulated calcium response in AGRP neurons. (a-c) Two-photon images of the ARC of a AGRPCRE mouse injected with viruses coding for Cre-dependent tdTomato and GCamp6. d Representative traces of GCamp6 fluorescence intensity over time in AGRP neurons from $\mathrm{AGRPCRE}^{\mathrm{M}} \mathrm{MRAP2}^{+/+}$(blue) and AGRPCRE$/ \mathrm{MRAP2}^{\mathrm{FL} / \mathrm{FL}}$ (red) mice. e Quantification of ghrelin-stimulated calcium responses in AGRP neurons from $\mathrm{AGRPCRE}^{\mathrm{M}} \mathrm{MRAP}^{+/+}$mice $\left(n=5\right.$ mice $/ 268$ neurons) and AGRPCRE$/ \mathrm{MRAP2} 2^{\mathrm{Fl} / \mathrm{Fl}}$ mice $\left(n=7\right.$ mice/415 neurons). Error bars are SEM. ${ }^{\star \star \star} p<0.001$ 

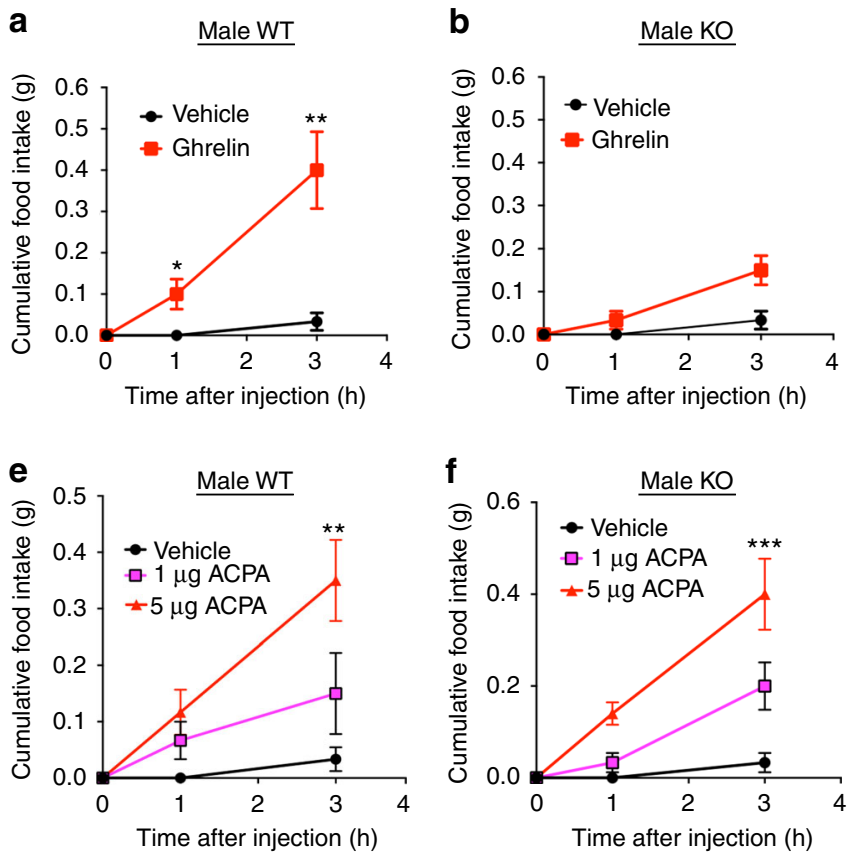
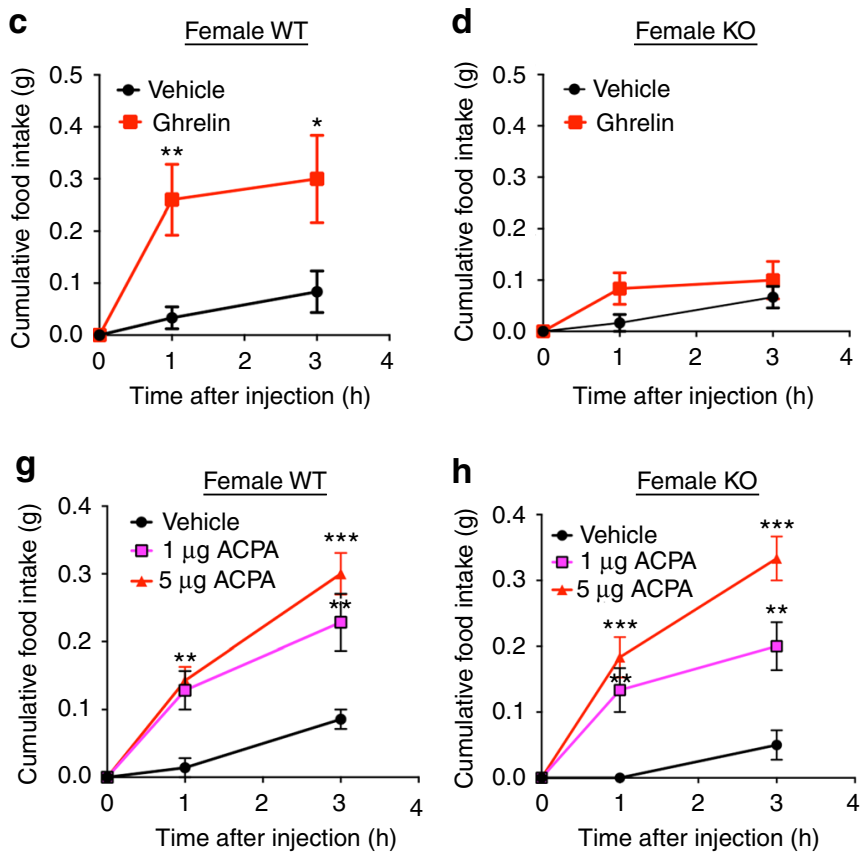

Fig. 7 MRAP2 is necessary for ghrelin to induce food intake. $\mathbf{a}$, b Food intake in satiated male WT (a) and Mrap2 KO (b) mice after ICV injection of saline or $13.25 \mu \mathrm{g}$ ghrelin $(n=6)$. c, d Food intake in satiated female WT (c) and Mrap2 KO (d) mice after ICV injection of saline or $13.25 \mu \mathrm{g}$ ghrelin $(n=6)$. e, $\mathbf{f}$ Food intake in satiated male WT (e) and Mrap2 KO (f) mice after ICV injection of saline or 1 or $5 \mu \mathrm{g}$ of the CB1R agonist ACPA ( $n=5 /$ group). $\mathbf{g}$, $\mathbf{h}$ Food intake in satiated female WT (g) and Mrap2 KO (h) mice after ICV injection of saline or 1 or $5 \mu \mathrm{g}$ of the CB1R agonist ACPA ( $n=5 /$ group). Error bars are SEM. ${ }^{\star \star} p<0.01,{ }^{\star \star \star} p<0.001$

for CRE-dependent tdTomato and the GCamp6 calcium reporter unilaterally in the ARC. About 2 weeks after viral injection, brain slices containing the ARC were placed in the perfusion chamber of a two-photon microscope for fluorescence imaging (Fig. 6a-c). Slices were perfused with artificial cerebrospinal fluid (aCSF) followed by aCSF supplemented with $10 \mathrm{nM}$ ghrelin, and GCamp6 fluorescence intensity was recorded over time in all AGRP neurons (tdTomato-positive) present in the field. At the end of the recording, slices were perfused with $\mathrm{KCl}$ to induce depolarization and allow the identification of all responsive neurons. We found that ghrelin induces calcium oscillations in AGRP neurons (Fig. 6d) with an average amplitude greater than threefold over baseline (Fig. 6e). Deletion of MRAP2 specifically in AGRP neurons significantly decreased the efficacy of ghrelin since the amplitude of the calcium response in AGRP neurons of AGRP $^{\mathrm{CRE}} / \mathrm{MRAP}^{\mathrm{fl} / \mathrm{fl}}$ mice was below twofold over baseline (Fig. 6d, e). No difference in the overall number of AGRP neurons was measured in the ARC of AGRPCRE $/ \mathrm{MRAP}^{+/+}$and $\mathrm{AGRP}^{\mathrm{CRE}} / \mathrm{MRAP}^{\mathrm{fl} / \mathrm{fl}}$ mice (Supplementary Fig. 3). This result demonstrates that, in agreement with our in vitro data, MRAP2 potentiates GHSR1a signaling in AGRP neurons.

Ghrelin fails to stimulate food intake in MRAP2 KO mice. It is well established that central injection of satiated mice with ghrelin causes a rapid and significant increase in food intake due to activation of hunger signaling. We reasoned that since MRAP2 is essential for GHSR1a signaling, Mrap2 KO mice should have a diminished orexigenic response to ghrelin injection. To test this hypothesis, we cannulated the lateral ventricles of the brains of Mrap2 KO mice and WT siblings. After recovery from the surgery, the animals were handled daily for a week in a manner that mimics ICV injections, to reduce the stress of the procedure. On the day of the experiment, satiated mice were injected with saline or ghrelin, and returned to their cages where food intake was monitored for $3 \mathrm{~h}$. Whereas the injection of ghrelin in WT mice (both male and female) caused a significant increase in food intake compared to saline-injected animals (Fig. 7a, c), ghrelin injection in male and female Mrap2 KO mice did not significantly stimulate food intake (Fig. 7b, d). This result confirms that the ghrelin receptor requires MRAP2 to trigger the behavioral response to hunger. To assess the specificity of the regulation of hunger through the GHSR1a by MRAP2, we tested the effect of MRAP2 on a distinct orexigenic pathway by activating the cannabinoid receptor $1(\mathrm{CB} 1 \mathrm{R})^{23,24}$. To this end, satiated WT and Mrap2 KO mice in which the lateral ventricle had been cannulated were injected with saline or with the CB1R agonist arachidonylcyclopropylamide (ACPA), and food intake was monitored for $3 \mathrm{~h}$. ACPA caused a similar and significant increase in food intake compared to saline in both WT and Mrap2 KO animals of both genders (Fig. 7e-h). This finding demonstrates that MRAP2 is not necessary for CB1R signaling in vivo, and that the lack of hunger sensing in Mrap2 $\mathrm{KO}$ mice is due specifically to a defect in ghrelin signaling.

\section{Discussion}

This study identifies a new role of MRAP2 in the regulation of energy homeostasis. We show that MRAP2 is important for fasting-mediated activation of AGRP neurons and that MRAP2 strongly potentiates ghrelin signaling. MRAP2 has previously been shown to potentiate MC4R signaling to promote leanness ${ }^{10,11}$ and to inhibit the PKR1 ${ }^{12}$, an anorexigenic GPCR expressed in POMC neurons ${ }^{20}$. This new role of MRAP2 in the ARC further establishes the importance of MRAP2 in the regulation of energy homeostasis by the hypothalamus. Although the deletion of MRAP2 significantly decreases fasting-induced AGRP neuron activation and food intake post food deprivation, those phenotypes are not found in GHSR1a KO mice (Supplementary Fig. 2$)^{25}$, thus suggesting that they are not due to a loss of ghrelin signaling. It is however possible that developmental adaptations in the GHSR1a KO animal compensate for the absence of ghrelin 
signaling. Since we have shown that MRAP2 is not expressed in the embryo and only reaches normal expression levels around the time of weaning ${ }^{11}$, it is less likely that developmental adaptation take place in the Mrap2 KO mice. However, because the homeostatic neuronal network can remodel and compensate for the ablation of AGRP neurons in neonates ${ }^{8}$, compensation in the Mrap2 KO model cannot be ruled out.

We show that the deletion of MRAP2 does not cause a complete loss of ghrelin responsiveness both in vitro and in vivo since cells transfected with GHSR1a alone can elicit a small amount of IP3 production when stimulated with ghrelin, and direct ICV injection of ghrelin can induce some level of cFos expression in neurons of the Mrap2 $\mathrm{KO}$ mice.

While this study focuses on the role of MRAP2 in AGRP neurons, we show that the fasting-induced decrease in POMC expression is also diminished in Mrap2 $\mathrm{KO}$ mice. This may be due to the decreased inhibitory input from AGRP neurons onto POMC neurons or an indication that MRAP2 also plays an important role in POMC neurons where it is also expressed ${ }^{20}$.

Mrap2 KO mice develop severe obesity over time $e^{10},{ }^{12}$, a phenotype that is in apparent contradiction with the conclusion of this study since one would predict that a decrease in GHSR1a signaling, due to the deletion of MRAP2, would promote leanness. It is however important to remember that, as stated earlier, MRAP2 is not a specific regulator of GHSR1a but also modulate the activity of MC4R ${ }^{10,11}$, PKR $1,{ }^{12}$ and possibly other yet unidentified receptors involved in the regulation of energy homeostasis. Consequently, the phenotype of Mrap2 KO mice is the result of a complex deregulation of the hypothalamic energy homeostasis machinery and does not reflect specifically the effect of Mrap2 deletion on GHSR1a action. Later studies focusing on the manipulation of MRAP2 expression specifically in AGRP neurons will be necessary to determine the role of MRAP2 on the regulation of physiological actions of ghrelin.

This study also illustrates the promiscuity of MRAP2, which at first was thought to be a specific regulator of melanocortin receptors, and thus suggests that MRAP2 likely regulates several additional GPCRs. Identifying such GPCRs will improve our understanding of the global physiological roles of MRAP2. MRAP2 displays a high level of selectivity for the receptors it interacts with. For example, MRAP2 does not significantly modulate the activity of the $\beta 2$-adrenergic receptor, the melanocortin-3 receptor, or NPY receptors ${ }^{11}$. In this study, the normal orexigenic response to ACPA suggests that MRAP2 is not required for $\mathrm{CB} 1 \mathrm{R}$ function. The mechanisms involved in the selectivity of MRAP2 for a subset of GPCRs and its modulatory effects still remain to be elucidated.

Mice with a global or neuron-specific deletion of GHSR1a are resistant to diet-induced obesity and display improved insulin sensitivity ${ }^{26,27}$, suggesting that inhibiting ghrelin actions could promote weight loss and decrease insulin resistance. Additionally, the stimulation of the ghrelin pathway is a promising approach for the treatment of cachexia $^{28}$ and diabetic gastroparesis ${ }^{29}, 30$. Understanding how MRAP2 enhances the activity of GHSR1a activity may uncover new strategies to modulate ghrelin action and inform drug discovery efforts targeting GHSR1a.

\section{Methods}

Animals. C57BL/6N Mrap2 $\mathrm{KO}$ and Mrap2 floxed mice were generated by the Sanger Mouse Genetics Project. AGRPCRE/tdTomato animals were generated by

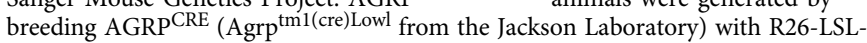
tdTomato reporter mice from the Jackson Laboratory. GHSRla KO mice were kindly provided by Dr. Jeffrey Zigman (University of Texas Southwestern, Dallas, TX, USA). All animals were maintained in the University of Iowa temperature controlled animal facility with $12 \mathrm{~h}$ light/dark cycles (6 a.m./6 p.m.). Animals were fed with standard rodent diet (NIH-31) and allowed free access to water. All experiments using mice were approved by the Animal Care and Use Committee at the University of Iowa.

Intracerebroventricular cannulation. Seven-week-old animals were anesthetized with intraperitoneal injection of a combination of xylazine and ketamine at dosage 10:100 mg/kg before being placed on a stereotaxic apparatus (David Kopf Instruments, Tujunga, CA, USA). After standard disinfection on surgical site, an incision was made to expose the skull and a small hole was drilled. A 26-gauge stainless steel cannula (PlasticOne) was placed into the left lateral ventricle (anteroposterior -0.3 $\mathrm{mm}$; medial lateral $+1.0 \mathrm{~mm}$; dorsal ventral $-2.1 \mathrm{~mm}$ ) and fixed in place with dental cement. Mice were allowed to recover for 7 days post surgery before experiments. At the end of the study, the localization of the injection site was confirmed by injecting $2 \mu$ l blue ink into the cannula.

cFos immunofluorescence. Animals were deeply anesthetized with saturated isoflurane in a closed chamber and perfused with ice cold $0.1 \mathrm{M}$ phosphate buffer solution (PBS; pH 7.4), followed by ice-cold $4 \%$ paraformaldehyde (PFA) in PBS. Whole brains were dissected out and post fixed in fresh $4 \%$ PFA for $12 \mathrm{~h}$ at $4{ }^{\circ} \mathrm{C}$ Brains were then immersed in $30 \%$ sucrose in PBS at $4^{\circ} \mathrm{C}$ until they sunk. Samples were embedded in Tissue-Tek OCT compound (Sakura Finetechical Co., Ltd., Tokyo) and sectioned at $35 \mu \mathrm{m}$ thickness using a cryostat (Leica Biosystems, Buffalo Grove, IL, USA). Free-floating sections were washed in PBS two times and incubated with blocking buffer containing 5\% normal goat serum in PBS with $0.5 \%$ Triton X-100 for $1 \mathrm{~h}$ followed by rabbit polyclonal anti-cFos antibody (Catalog (Cat.) No. sc 52, Santa Cruz Biotechnology, TX, USA) in blocking solution (1:1000) overnight at $4{ }^{\circ} \mathrm{C}$. After washed with PBS containing 0.1\% Tween-20 (PBST), the sections were incubated in 1:500 Alexa Fluor 594 goat anti-rabbit IgG (R37117, Thermo Fisher Scientific) for $1 \mathrm{~h}$ at room temperature. The sections were washed in PBST five times and mounted onto superFrost slides (Fisher Scientific, Pittsburgh, PA, USA), air-dried at room temperature in a dark room and coverslipped with Prolong diamond antifade mountant with 4,6-diamidino-2-phenylindole (Molecular Probes by Life Technologies, Carlsbad, CA, USA). For cell counting, three different sections of the ARC of hypothalamus in each mouse were examined using $\times 20$ magnification. cFos-positive cells were manually counted from entire ARC from five mice per group using the Olympus IX3 microscope system and Olympus Cellsens Dimension software.

Cell culture and transfections. CHO-K1, HEK293T, and CHO-M1 cells were cultured in Dulbecco's Modified Eagle's medium (DMEM) /F-12 supplemented with $5 \% \mathrm{v} / \mathrm{v}$ fetal bovine serum and $1 \%$ penicillin-streptomycin solution. Cultures were incubated at $37^{\circ} \mathrm{C}$ in a humidified atmosphere containing $5 \% \mathrm{CO}_{2}$. Cells were transfected using LipoD293 in vitro transfection reagent (Signagen, Rockville, MD, USA). The total amount of DNA transfected for each condition within an experiment was kept identical.

Co-immunoprecipitation and western blot. HEK293T cells were transfected with human MRAP2-3Flag and 3HA-GHSR1a using LipoD293 according to the manufacturer's protocol. At $24 \mathrm{~h}$ after transfection, the cells were lysed with ice-cold non-denaturing lysis buffer containing $0.1 \% n$-dodecyl- $\beta$-maltoside in PBS with proteinase inhibitor and incubated at $4{ }^{\circ} \mathrm{C}$ for $10 \mathrm{~min}$ on an orbital shaker, followed by centrifugation at $15,000 \times g$ for $10 \mathrm{~min}$. The protein lysates were transferred into new centrifuge tubes and following antibodies, Purified mouse anti-HA.11 epitope tag antibody (Biolegend, USA) or M2 mouse anti-Flag (Sigma-Aldrich, St. Louis, MO, USA), were added into the cell lysates at $1 / 5000$ dilution. The protein lysates were then incubated on a shaker for overnight at $4{ }^{\circ} \mathrm{C}$. $20 \mu \mathrm{l}$ of protein $\mathrm{G}$ dynabeads (Life Technologies) were added into each sample and incubated at $4{ }^{\circ} \mathrm{C}$ for $1 \mathrm{~h}$. The beads were washed four times with wash buffer and sample buffer containing LDS loading buffer with $5 \% \beta$-mercaptoethanol was added on the beads to elude the target protein and antibodies and boiled $5 \mathrm{~min}$. The same amount of protein from each sample was separated by SDS-polyacrylamide gel electrophoresis on $10 \%$ gel and transferred to polyvinylidene fluoride membranes. The proteins were detected by western blot using mouse anti-HA for GHSR1a co-immunoprecipitation experiments and mouse anti-Flag for detecting MRAP2. After $1 \mathrm{~h}$ in blocking solution containing 5\% milk in PBS with $0.1 \%$ Tween-20, the membranes were incubated with the primary antibody diluted $1 / 5000$ in blocking solution overnight at $4{ }^{\circ} \mathrm{C}$. The membranes were washed with PBST for $5 \mathrm{~min}$ three times and then incubated with secondary goat anti-mouse horseradish peroxidase (HRP) antibody (Cat. No. 170-6516, Bio-Rad Laboratories Inc, USA) at 1/5000 dilution for $45 \mathrm{~min}$ at room temperature followed by four washes with PBST. The WesternSure ECL substrate was applied on the membrane to detect the HRP-labeled secondary antibodies on the membrane and imaged on an cDigit scanner (LI-COR, NE, USA).

NanoBit protein-protein interaction assay. $\mathrm{CHO}$ cells were transfected with GFP, 3HA-GHSR1a-LgBit + FKBP-SmlBit, FRB-LgBit + MRAP2-SmlBit, or 3HAGHSR1a-LgBit + MRAP2-SmlBit. FKBP and FRB do not interact with GHSR1a and MRAP2, respectively, and were used to measure nonspecific NanoLuc recombination (Promega). Transfected cells were plated in a white opaque 96-well plate and allowed to attach overnight. Live-cell NanoBit substrate was added to the 
cells following the manufacturer's direction and luminescence was measured $5 \mathrm{~min}$ later using a Spectramax i3 plate reader (Molecular Devices).

Western blot for MRAP2-V5 or pAMPK from ARC. Ad libitum-fed or $24 \mathrm{~h}$ fasted mice were deeply anesthetized with isoflurane before removing the brain. ARC was isolated by microdissection and solubilized in lysis buffer ( $38.5 \mathrm{mM}$ Tris$\mathrm{HCl}, 1 \mathrm{mM}$ EGTA, $1 \mathrm{mM}$ EDTA, $1 \%$ Triton-X 100, $1 \mathrm{mM}$ sodium orthovanadate, $50 \mathrm{mM}$ sodium fluoride, $5 \mathrm{mM}$ sodium pyrophosphate, and $250 \mathrm{mM}$ sucrose) with protease inhibitor on ice. Protein concentration was determined by bicinchoninic acid assay and the same amount of protein was loaded on polyacrylamide gels for SDS separation. Western blot was performed using either anti-V5 (Cell Signaling Technology, Rabbit mAb \#13202) or anti-pAMPK (Cell Signaling Technology Rabbit mAb \#2535)

Quantitative PCR. After $24 \mathrm{~h}$ fasting, 11-week-old animals were deeply euthanized with saturated isoflurane in a closed chamber. Fresh whole hypothalami were collected into an ice-chilled tube and immediately frozen in dry ice and kept at $-80^{\circ} \mathrm{C}$. Well-fed animals were used as control groups. Total RNA was extracted from hypothalamus using RNeasy lipid tissue mini kit (Qiagen, Germany) according to the manufacturer's instruction and treated with RQ1 RNase-free DNase enzyme (Promega, USA). A unit of $1 \mu \mathrm{g}$ cDNA was synthesized using iScript reverse transcription kit for reverse transcription (RT)-qPCR according to the manufacturer's instruction (Bio-Rad, USA). Gene expression was quantified using mouse-specific predesigned probe-based quantitative PCR ( $\mathrm{qPCR}$ ) assays (IDT, USA) in $20 \mu \mathrm{l}$ of PCR mixture containing $1 \times$ KAPA Probe Fast qPCR master mix (Kapa Biosystems, MA, USA), 50 ng of cDNA (Bio-Rad), $200 \mathrm{nM}$ of each primer, and FAM/BHQ-1 hydrolysis probe. Quantitative real-time PCR was done in optical 96-well plates on an iCycler (Bio-Rad) using a fast cycling protocol; $95^{\circ} \mathrm{C}$ for $3 \mathrm{~min}$ followed by 40 cycles of $3 \mathrm{~s}$ at $95^{\circ} \mathrm{C}$ and $20 \mathrm{~s}$ at $60^{\circ} \mathrm{C}$. The beta actin mRNA level was quantified as an endogenous control. The amount of cDNA in unknown samples was determined from a standard curve method. The target cDNA was compared to the amount of beta actin.

Primer sequences. Primer sequences were as follows. Mouse Mrap2: primer 1, AGTCTGACACAAAGCTGTTCA; primer 2, GATTGGATTCTGGGTTGGTCT; probe, /56-FAM/TGTCTTCGT/ZEN/CAGCAAAGTCAGCACA/3IABkFQ/.

Mouse Pomc: primer 1, CTGTTCATCTCCGTTGCCA; primer 2 CATAGATGTGTGGAGCTGGTG; probe, /56-FAM/AGCGAGAGG/ZEN/ TCGAGTTTGCAAGC/3IABkFQ/

Mouse Agrp: primer 1, CAACAGCAGAACACAACTCAG; primer 2, GCACAAGAGACCAGGACATC; probe, /56-FAM/AGATCAGCA/ZEN/ AGCAAAGGCCATGC/3IABkFQ/.

Mouse Npy: primer 1, ACAAGTTTCATTTCCCATCACC; primer 2, ACATCAATCTCATCACCAGACAG; probe, /56-FAM/CCCAGAACA/ZEN/ AGGCTTGAAGACCCT/3IABkFQ/.

Mouse $\beta$-actin: primer 1, AGGTCTTTACGGATGTCAACG; primer 2 , ATTGGCAACGAGCGGTT; probe, /56-FAM/ATTCCATAC/ZEN/ CCAAGAAGGAAGGCTGG/3IABkFQ/.

Immunofluorescent staining for MRAP2. We bred AgRPCRE mice (\#012899, Jackson Laboratories) with R26-LSL-tdTomato reporter mice to study the expression of Mrap2 protein in the AgRP neuron in the ARC of the hypothalamus. AgRPCRE/tdTomato male mice were perfused with $4 \%$ PFA in $0.1 \mathrm{M}$ phosphate buffer, $\mathrm{pH} 7.4$, whole brains were dissected out and post-fixed in fresh $4 \%$ PFA overnight at $4{ }^{\circ} \mathrm{C}$. The brains were cryopreserved by incubating in $30 \%$ sucrose in $0.1 \mathrm{M}$ phosphate buffer. Cryosections were cut at $40 \mu \mathrm{m}$ thickness and incubated in $10 \mathrm{mM}$ sodium citrate at $80^{\circ} \mathrm{C}$ for $30 \mathrm{~min}$. The sections were then blocked in $5 \%$ normal goat serum $/ 0.4 \%$ Triton X-100 in PBS for $1 \mathrm{~h}$ and subsequently incubated with rabbit anti-MRAP2 antibody (Novus Biologicals) 1:1000 in blocking buffer overnight at $4{ }^{\circ} \mathrm{C}$. The sections were washed with $0.1 \%$ Tween-20 in PBS three times and incubated with goat anti-rabbit Alexa Fluor 488 antibody 1:300 for $1 \mathrm{~h}$ in blocking buffer and washed four times with $0.1 \%$ Tween-20 in PBS before mounting on a glass slide. Slides were visualized with an Olympus IX83 inverted fluorescence microscope.

Inositol phosphate assay. Total inositol 1 phosphate (IP1) level was measured $48 \mathrm{~h}$ after transfection in adherent cells plated in a 384-well white opaque plate at a density of 14,000 cells/well. CHO-M1 cells (CHO cells stably expressing the muscarinic receptor) were transfected with MRAP2 alone, GHSRla and empty vector, or GHSR1a and MRAP2 at a 1:5 ratio and plated in a 384-well plate the next day. IP1 accumulation was measured using the IP-One Tb HTRF kit (Cisbio Bioassays) according to the manufacturer's instructions. Signals at 665 and $620 \mathrm{~nm}$ were detected using Spectramax i3 (Molecular Devices) equipped with a Cisbio HTRF module. Results were normalized to the signal obtained in response to $10 \mu \mathrm{M}$ Carbachol for each condition.

Food intake and energy expenditure measurement. For measurements of cumulative food intake, mice were individually housed in standard cages and, after
7 days of acclimation, food consumption was measured daily at 10.00 a.m. For energy expenditure, food intake, and activity measurements, 7-week-old male mice were individually housed in the home cage for 1 week before housed in CLAMS center feeder cages for 5 days. Data such as food intake, oxygen consumption, heat, and locomotion were collected automatically over a 5-day period and then analyzed with the Oxymax/CLAMS software. Daily food intake and activity data over the experimental period were collapsed to generate average daily food consumption and activity. Heat production was analyzed using analysis of covariance (ANCOVA)

Fixed-cell ELISA. The CHO-K1 cells were cultured in a 24 -well plate and transfected transiently with 3HA-GHSR1a and MRAP2, 3HA-GHSR1a and empty vector, or empty vector only. The fixed-cell ELISA was performed at $24 \mathrm{~h}$ after the transfection as described previously (eLife paper). After washing with PBS, the cells were fixed with $4 \%$ PFA in PBS for 10 min and washed with PBS twice, blocked with either $5 \%$ milk in PBS for surface-expression measurement or $5 \%$ milk in RIPA lysis buffer containing $150 \mathrm{mM} \mathrm{NaCl}, 50 \mathrm{mM}$ Tris, $1 \mathrm{mM}$ EDTA, $1 \%$ Triton $\mathrm{X}-100,0.1 \%$ SDS, and $0.5 \%$ sodium deoxycholate, $\mathrm{pH} 8.0$, for total receptor expression measurement for $45 \mathrm{~min}$. Cells were subsequently incubated with 1 / 5000 mouse anti-HA monoclonal antibody in the blocking buffer for $2 \mathrm{~h}$ at room temperature and washed for $5 \mathrm{~min}$ three times with PBS followed by incubation with $1 / 5000$ anti-mouse-HRP antibody for $1 \mathrm{~h}$ at room temperature before the cells were washed with PBS for 5 min three times. A volume of $200 \mu$ lof ELISA substrate (3,3',5,5'-Tetramethylbenzidine, Sigma-Aldrich) was added into each well and reaction was stopped with $10 \%$ sulfuric acid when blue color was visible. Absorbance of ELISA reaction was measured at $450 \mathrm{~nm}$ using a Spectramax I3 plate reader.

Stereotaxic injection. Mice were anesthetized in accordance with University of Iowa Carver College of Medicine guidelines. Mice were placed into stereotaxic frame and injection of $5 \mu \mathrm{lAAV1-GCamp6s}$ virus and $5 \mu \mathrm{l} \mathrm{AAV1-flox-tdTomato}$ (UPenn vector core) were injected unilaterally into the ARC of the hypothalamus (bregma $-1.6, \mathrm{M} / \mathrm{L}+0.2$, and $\mathrm{D} / \mathrm{V}-5.4$ ) with a flow rate of $1 \mu \mathrm{l} / 5 \mathrm{~min}$. At completion of injection, needle was kept in injection site for an additional $15 \mathrm{~min}$. Mice recovered from surgery for 7 days and tissue was processed for analysis 7-14 days after injection.

Multiphoton imaging. Coronal slices $(400 \mu \mathrm{m})$ from AAV1-GCamp6s/AAV1flox-tdTomato-injected mice were prepared, in accordance with University of Iowa Carver College of Medicine guidelines. Slices were cut using a Vibratome 1000 Plus (Vibratome, St. Louis, MO, USA) in ice-cold slicing buffer (127 mM NaCl, $26 \mathrm{mM}$ $\mathrm{NaHCO}$, 1.2 mM KH2PO4, $1.9 \mathrm{mM} \mathrm{KCl}, 1.1 \mathrm{mM} \mathrm{CaCl} 2,2 \mathrm{mM} \mathrm{MgSO} 4$, and 10 $\mathrm{mM}$ D-glucose) bubbled with $95 \% \mathrm{O} 2$ and 5\% CO2. Slices were then transferred to a holding chamber containing oxygenated aCSF $(127 \mathrm{mM} \mathrm{NaCl}, 26 \mathrm{mM} \mathrm{NaHCO} 3$ $1.2 \mathrm{mM} \mathrm{KH} 2 \mathrm{PO} 4,1.9 \mathrm{mM} \mathrm{KCl}, 2.2 \mathrm{mM} \mathrm{CaCl} 2,1 \mathrm{mM} \mathrm{MgSO} 4$, and $10 \mathrm{mM} \mathrm{D}$ glucose) for $30 \mathrm{~min}$ at $34^{\circ} \mathrm{C}$ and then for another $30 \mathrm{~min}$ at $22^{\circ} \mathrm{C}$ for recovery, and subsequently transferred to a submersion recording chamber continually perfused with $32{ }^{\circ} \mathrm{C}$ oxygenated aCSF (rate: $2 \mathrm{ml} / \mathrm{min}$ ). Slices were then placed in the Olympus FVMPE-RS multiphoton scanning microscope and equilibrated for at least $15 \mathrm{~min}$ before each recording. Baseline GCamp6 signal was recorded for the first $5 \mathrm{~min}$ and then slice was perfused with $10 \mathrm{nM}$ ghrelin for $15 \mathrm{~min}$. Peak fluorescence during the $15 \mathrm{~min}$ ghrelin perfusion was normalized to baseline measurements for each neuron recorded. At the end of the experiment, slices were perfused with high-potassium solution (127 mM KCl, $26 \mathrm{mM} \mathrm{NaHCO} 3,1.2 \mathrm{mM}$ $\mathrm{KH} 2 \mathrm{PO} 4,1.9 \mathrm{mM} \mathrm{KCl}, 2.2 \mathrm{mM} \mathrm{CaCl} 2,1 \mathrm{mM} \mathrm{MgSO} 4$, and $10 \mathrm{mM}$-glucose) to induce depolarization and ensure cell viability.

Effect of ghrelin and ACPA on food intake. Ghrelin-induced spontaneous food intake was observed in ad libitum Mrap2 KO mice and WO littermates during the light phase from 10 a.m. to 1 p.m. WT and Mrap2 KO mice were cannulated in the lateral ventricle and individually housed. After recovering from the surgery, mice were acclimated to handling for 7 days before the behavioral test was started. Animals received a slow single ICV injection of either $3 \mu$ l of sterile normal saline, $13.5 \mu \mathrm{g}$ rat ghrelin (Tocris Bioscience, Cat. No. 1465), $1 \mu \mathrm{g}$ ACPA, or $5 \mu \mathrm{g}$ ACPA (Tocris Bioscience, Cat. No. 1318) over a 1 min period using a $25 \mu$ l Hamilton syringe coupled to an injection cannula by a polyethylene tubing. After injection the injector was kept in place for 3 min to ensure full diffusion from the injector tip. Food intake was monitored at 0,1 , and $3 \mathrm{~h}$ after injection.

Statistical analysis. Statistical difference was analyzed using GraphPad Prism 6 program (Graph Pad software, San Diego, CA, USA). The data were shown as mean \pm SEM. One-way analysis of variance (ANOVA) followed by post hoc Tukey test or unpaired $t$-test or regular two-way ANOVA was used to determine statistically significant differences between the groups tested time points and different samples. Energy expenditure data were analyzed by ANCOVA. $p<0.05$ was taken as the level of significance in all statistical analyses.

Data availability. All data included in this study are available upon request. 
Received: 7 December 2016 Accepted: 25 July 2017

Published online: 28 September 2017

\section{References}

1. Cone, R. D. et al. The arcuate nucleus as a conduit for diverse signals relevant to energy homeostasis. Int. J. Obes. Relat. Metab. Disord. 25(Suppl 5): S63-S67 (2001).

2. Schwartz, M. W., Woods, S. C., Porte, D. Jr., Seeley, R. J. \& Baskin, D. G. Central nervous system control of food intake. Nature 404, 661-671 (2000).

3. Kojima, M. et al. Ghrelin is a growth-hormone-releasing acylated peptide from stomach. Nature 402, 656-660 (1999).

4. Tschop, M., Smiley, D. L. \& Heiman, M. L. Ghrelin induces adiposity in rodents. Nature 407, 908-913 (2000).

5. Chen, H. Y. et al. Orexigenic action of peripheral ghrelin is mediated by neuropeptide Y and agouti-related protein. Endocrinology 145, 2607-2612 (2004).

6. Kamegai, J. et al. Chronic central infusion of ghrelin increases hypothalamic neuropeptide Y and Agouti-related protein mRNA levels and body weight in rats. Diabetes 50, 2438-2443 (2001).

7. Nakazato, M. et al. A role for ghrelin in the central regulation of feeding. Nature 409, 194-198 (2001)

8. Luquet, S., Perez, F. A., Hnasko, T. S. \& Palmiter, R. D. NPY/AgRP neurons are essential for feeding in adult mice but can be ablated in neonates. Science 310, 683-685 (2005)

9. Wang, Q. et al. Arcuate AgRP neurons mediate orexigenic and glucoregulatory actions of ghrelin. Mol. Metab. 3, 64-72 (2014).

10. Asai, M. et al. Loss of function of the melanocortin 2 receptor accessory protein 2 is associated with mammalian obesity. Science 341, 275-278 (2013).

11. Sebag, J. A., Zhang, C., Hinkle, P. M., Bradshaw, A. M. \& Cone, R. D. Developmental control of the melanocortin-4 receptor by MRAP2 proteins in zebrafish. Science 341, 278-281 (2013).

12. Chaly, A. L., Srisai, D., Gardner, E. E. \& Sebag, J. A. The Melanocortin Receptor Accessory Protein 2 promotes food intake through inhibition of the Prokineticin Receptor-1. Elife 5, e12397 (2016).

13. Anderson, E. J. et al. 60 YEARS OF POMC: regulation of feeding and energy homeostasis by alpha-MSH. J. Mol. Endocrinol. 56, T157-T174 (2016).

14. Fan, W., Boston, B. A., Kesterson, R. A., Hruby, V. J. \& Cone, R. D. Role of melanocortinergic neurons in feeding and the agouti obesity syndrome. Nature 385, 165-168 (1997).

15. Beale, K. et al. Peripheral administration of prokineticin 2 potently reduces food intake and body weight in mice via the brainstem. Br. J. Pharmacol. 168, 403-410 (2013).

16. Szatkowski, C. et al. Prokineticin receptor 1 as a novel suppressor of preadipocyte proliferation and differentiation to control obesity. PLOS ONE 8 e81175 (2013)

17. Betley, J. N. et al. Neurons for hunger and thirst transmit a negative-valence teaching signal. Nature 521, 180-185 (2015).

18. $\mathrm{Wu}, \mathrm{Q}$. et al. The temporal pattern of cfos activation in hypothalamic, cortical, and brainstem nuclei in response to fasting and refeeding in male mice. Endocrinology 155, 840-853 (2014).

19. Hahn, T. M., Breininger, J. F., Baskin, D. G. \& Schwartz, M. W. Coexpression of Agrp and NPY in fasting-activated hypothalamic neurons. Nat. Neurosci. 1, 271-272 (1998)

20. Henry, F. E., Sugino, K., Tozer, A., Branco, T. \& Sternson, S. M. Cell typespecific transcriptomics of hypothalamic energy-sensing neuron responses to weight-loss. Elife 4, doi:10.7554/eLife.09800 (2015).

21. Havel, P. J. Peripheral signals conveying metabolic information to the brain: short-term and long-term regulation of food intake and energy homeostasis. Exp. Biol. Med. (Maywood) 226, 963-977 (2001)
22. Kirchner, H., Tong, J., Tschop, M. H. \& Pfluger, P. T. Ghrelin and PYY in the regulation of energy balance and metabolism: lessons from mouse mutants. Am. J. Physiol. Endocrinol. Metab. 298, E909-E919 (2010).

23. Williams, C. M., Rogers, P. J. \& Kirkham, T. C. Hyperphagia in pre-fed rats following oral delta9-THC. Physiol. Behav. 65, 343-346 (1998).

24. Koch, J. E. Delta(9)-THC stimulates food intake in Lewis rats: effects on chow high-fat and sweet high-fat diets. Pharmacol. Biochem. Behav. 68, 539-543 (2001).

25. Sun, Y., Butte, N. F., Garcia, J. M. \& Smith, R. G. Characterization of adult ghrelin and ghrelin receptor knockout mice under positive and negative energy balance. Endocrinology 149, 843-850 (2008).

26. Zigman, J. M. et al. Mice lacking ghrelin receptors resist the development of diet-induced obesity. J. Clin. Invest. 115, 3564-3572 (2005).

27. Lee, J. H. et al. Neuronal deletion of ghrelin receptor almost completely prevents diet-induced obesity. Diabetes 65, 2169-2178 (2016)

28. Muller, T. D., Perez-Tilve, D., Tong, J., Pfluger, P. T. \& Tschop, M. H. Ghrelin and its potential in the treatment of eating/wasting disorders and cachexia. $J$. Cachexia Sarcopenia Muscle 1, 159-167 (2010).

29. Murray, C. D. et al. Ghrelin enhances gastric emptying in diabetic gastroparesis: a double blind, placebo controlled, crossover study. Gut 54, 1693-1698 (2005)

30. Shin, A. \& Wo, J. M. Therapeutic applications of ghrelin agonists in the treatment of gastroparesis. Curr. Gastroenterol. Rep. 17, 430 (2015)

\section{Acknowledgements}

This work was supported by J.A.S. startup funds provided by the Department of Molecular Physiology and Biophysics and the F.O.E.D.R.C at the University of Iowa.

\section{Author contributions}

D.S., T.C.Y., and J.A.S. designed experiments, performed experiments, analyzed the data and wrote the manuscript. A.A.L. and A.A.J.R. performed experiments, analyzed the data, and edited the manuscript. N.A.P. performed experiments and J.L.G. designed experiments and analyzed the metabolic data.

\section{Additional information}

Supplementary Information accompanies this paper at doi:10.1038/s41467-017-00747-6.

Competing interests: The authors declare no competing financial interests.

Reprints and permission information is available online at http://npg.nature.com/ reprintsandpermissions/

Publisher's note: Springer Nature remains neutral with regard to jurisdictional claims in published maps and institutional affiliations.

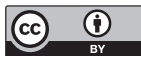

Open Access This article is licensed under a Creative Commons Attribution 4.0 International License, which permits use, sharing adaptation, distribution and reproduction in any medium or format, as long as you give appropriate credit to the original author(s) and the source, provide a link to the Creative Commons license, and indicate if changes were made. The images or other third party material in this article are included in the article's Creative Commons license, unles indicated otherwise in a credit line to the material. If material is not included in the article's Creative Commons license and your intended use is not permitted by statutory regulation or exceeds the permitted use, you will need to obtain permission directly from the copyright holder. To view a copy of this license, visit http://creativecommons.org/ licenses/by/4.0/.

(c) The Author(s) 2017 